\title{
LABORATORY EXAMINATIONS FOR GONOCOCCAL INFECTION IN THE FEMALE
}

\author{
BY \\ K. E. COOPER, A. MAYR-HARTING, and A. E. W. McLACHLAN \\ From the Departments of Preventive Medicine and Venereal Diseases, \\ Bristol University
}

Gonorrhœa is an infection by the organism Neisseria gonorrhea, and this diagnosis must not be made unless the causal organism is demonstrated. It follows that, although it may not always be possible to show the presence of this organism in all cases, the only proof that a clinical suspicion is a fact is by such a demonstration. Accuracy of diagnosis thus becomes a question of efficiency of isolation and subsequent identification of the gonococcus.

Such proof necessitates isolation of the organism in pure culture, and identification by its sugar reactions. Supporting evidence may be obtained from smears and serological tests, but these have obvious limitations. It is possible on occasion to obtain epidemiological evidence of the probability of the gonococcal nature of an infection by showing that contacts undoubtedly suffering from gonorrhœa have been infected by a particular patient, although the findings in the latter may be negative.

This paper attempts to estimate the value of the routine methods in use in this laboratory, mainly during the years 1945 and 1946. In the light of this evidence and that of other workers, we describe those features which we regard as of most importance in achieving a diagnosis.

\section{The Limitations of Smears}

Bacteriologists are less sure today than they were in the early years after its discovery of identifying the gonococcus on morphological grounds alone. Even when care is taken to avoid confusion with decolorized Gram-positive organisms, or with coccal forms of bacilli, the possibility of the presence of other morphologically similar organisms of this Neisseria group must be remembered. Opinions on morphology alone are given less dogmatically than they were. McLeod (1947) has repeatedly drawn attention to the presence in routine smears of Gram-negative diplococci, which are not gonococci.
It has been the practice in this laboratory during the last ten years to report the presence of Gramnegative diplococci in smears as being of typical appearance only when they were intracellular, and when other Gram-negative organisms were not sufficiently numerous to lead to error by their appearance due to decolorization or phagocytosis. The results quoted in this paper indicate that in only 0.4 per cent. of the 1,792 cases considered negative on final assessment was such a "positive" report given, and that smears reported as positive were obtained by repeated examination at least once in 49.9 per cent. of the 369 cases finally considered to be suffering from gonorrhœa. It is evident that these severe criteria, though fairly successful in avoiding false positive smear readings, miss half the cases (Table I).

TABLE I

ASSESSMENT OF CASES

\begin{tabular}{|c|c|c|c|c|c|c|c|c|}
\hline \multirow{3}{*}{$\begin{array}{c}\text { Final } \\
\text { assessment } \\
\text { of } \\
\text { Patient }\end{array}$} & \multicolumn{6}{|c|}{ Smear } & \multirow{2}{*}{\multicolumn{2}{|c|}{ Total }} \\
\hline & \multicolumn{2}{|c|}{ Typical } & \multicolumn{2}{|c|}{ Suspicious } & \multicolumn{2}{|c|}{$\begin{array}{c}\text { Negative } \\
\text { or } \\
\text { Doubtful }\end{array}$} & & \\
\hline & No. & $\%$ & No. & $\%$ & No. & $\%$ & No. & $\%$ \\
\hline Positive* & 184 & $49 \cdot 9$ & 127 & 34.4 & 58 & $\mid 15 \cdot 7$ & 369 & 100 \\
\hline Negative* & 7 & 0.4 & 273 & 15.2 & 1,512 & $84 \cdot 4$ & 1,792 & 100 \\
\hline
\end{tabular}

* Patient positive (or negative) is the retrospective diagnosis reached after weighing up the whole history, examination, epidemiology, of each patient, after completion of all the laboratory investigations.

We have therefore reported Gram-negative diplococci, in the presence of other organisms likely to cause confusion, which were morphologically indistinguishable from the gonococcus, whether intracellular or extracellular, as giving a smear of 'suspicious' appearance, reserving the report 'doubtful' for any atypical organisms that could not with certainty be dismissed as negative. This method of 
division drew attention to another 34.4 per cent. of the gonococcal cases, as this number had suspicious smears; but no great reliance could be placed on such a finding, as $15 \cdot 2$ per cent. of the non-gonococcal cases also had such smears. Evidence that the smear method is very defective in the detection of cases is given by the fact that 15.7 per cent. of the positive cases had negative or doubtful smears on all occasions on which they were examined. It should be emphasized that all these results have been obtained from repeated examinations of the patients, and that the most definite result is taken as being of most significance. The similarity in the percentages of missed cases (doubtful or negative) and of false positives, if the suspicious smear were taken as diagnostic, shows that the smear method as at present practised is unreliable, and that morphological characters alone are quite insufficient for the diagnosis of gonorrhœa. If a "typical" finding is not obtained in five to seven minutes' microscopic examination, then only in an occasional case will there be a positive finding.

\section{The Accuracy of Culture}

Culture methods on the other hand, allowing as they do a full investigation of the cultural and biochemical characteristics of the organism, can identify the gonococcus with certainty. There is no question of false positives if the laboratory examinations are complete; there is only the difficulty of culture and the relative sensitivity of the different methods available. With the - selective methods described in this paper, at least one culture was obtained pure from each patient suffering from gonorrhœa, and was identified by sugar fermentations. Most authorities agree that with reasonable control and facilities the culture method ought to be more sensitive as well as more certain than the smear method (McLeod, 1947). Where such difficulties as war conditions exist, reliability is not always achieved, especially in the diagnosis of gonorrhœa in the female, as is shown in the valuable paper by King and Gallagher (1946).

The culture methods advocated by McLeod are adequate for most gonococci (McLeod and others, 1934), and recent improvements have even increased the number of delicate strains that can be isolated by culture. In this laboratory the modification of McLeod's medium described by Harber (1947) has been further improved by substituting " Proteose peptone No. 3 " for " Neo-peptone", and by adding soluble starch to neutralize the toxic effect of some batches of agar. Careful control of the other conditions of incubation is necessary: temperature $36^{\circ} \mathrm{C}$. ; atmosphere that of a closed jar in which a candle has become extinguished by lack of oxygen (the production of $\mathrm{CO}_{2}$ and water vapour are both important); the use of agar sufficiently soft to retain enough moisture ; and the use of these plates without preliminary drying and within a few days of pouring. All these precautions can most satisfactorily be taken in a large bacteriological laboratory, but we have found great difficulty in maintaining their observance in small clinic laboratories. If, however, such culture methods are successfully achieved only in a few central laboratories, then means must be devised for the satisfactory transport of material from clinics to the laboratories.

\section{TABLE II}

CULTURE AND SMEAR RESULTS COMPARED WITH THE ULTIMATE ASSESSMENT

\begin{tabular}{|c|c|c|c|c|c|}
\hline \multirow[b]{2}{*}{ Culturz } & \multicolumn{3}{|c|}{ Smear } & \multirow[b]{2}{*}{ Total } & \multirow{5}{*}{$\begin{array}{c}\text { Total } \\
\text { positive } \\
\text { patients: } \\
352\end{array}$} \\
\hline & $\begin{array}{c}\text { Typi- } \\
\text { cal }\end{array}$ & $\begin{array}{l}\text { Suspi- } \\
\text { cious }\end{array}$ & $\begin{array}{l}\text { Nega- } \\
\text { tive or } \\
\text { doubt- } \\
\text { ful }\end{array}$ & & \\
\hline $\begin{array}{c}\text { Positive : } 307 \\
\text { Final assess- } \\
\text { ment } \\
\text { Positive }\end{array}$ & 159 & 100 & 48 & 307 & \\
\hline \multirow[t]{2}{*}{$\begin{array}{c}\text { Negative: } 1,854 \\
\begin{array}{c}\text { Final assess- } \\
\text { ment }\end{array} \\
\text { Positive } \\
\text { Negative }\end{array}$} & $\begin{array}{r}22 \\
7 \\
3\end{array}$ & $\begin{array}{r}13 \\
273 \\
14\end{array}$ & $\begin{array}{r}10 \\
1,512 \\
0\end{array}$ & $\begin{array}{r}45 \\
1,792 \\
17\end{array}$ & \\
\hline & 191 & 400 & 1,570 & 2,161 & \\
\hline
\end{tabular}

Many methods have been advocated for this purpose (Eldering and Palser, 1946 ; Stuart, 1946 ; Harber, 1947). During the collection of the results embodied in this paper we have used Harber's modification of Cox and McDermott's crystalviolet/blood mixture for the transport of swabs. We have, however, since the completion of these results substituted 1/5000 thallium acetate for crystal violet, as this mixture is even more efficacious in inhibiting the local contaminants which so often destroy the gonococcus during transport. The superiority of this latter mixture was demonstrated by Cooper and Linton (1947). The results in Table II, however, were obtained with the crystalviolet mixture.

Table II shows the cultural and smear results compared with the ultimate assessment. The figures refer to the number of patients examined, and not to the number of cultures or smears. The significance of these results is therefore that of repeated examination of the patients by these methods, with rarely less than three smears and cultures, and sometimes as many as twelve from one patient. 
The most definitely positive single result obtained during these procedures is taken as the recorded finding for that patient.

A number is also included for clinically positive patients who had negative laboratory findings throughout. The evidence was epidemiological, contacts having been infected with the gonococcus. This number is of course small, and the clinically and bacteriologically negative cases may include some missed cases. This difficulty has been shown to exist elsewhere, however, by figures published from other laboratories.

TABLE III

CULTURE AND SMEAR RESULTS AS GIVEN BY DIFFERENT AUTHORS

\begin{tabular}{|c|c|c|c|c|}
\hline Female patients & & $\underset{(1942-5)}{\text { King }}$ & $\underset{(1947)}{\text { McLeod }}$ & $\begin{array}{l}\text { Bristol } \\
(1945-6)\end{array}$ \\
\hline $\begin{array}{l}\text { Positive results : } \\
\text { Culture only } \ldots \\
\text { Smear only } \ldots \\
\text { Smear and culture }\end{array}$ & $\begin{array}{l}\cdots \\
\cdots \\
\ldots\end{array}$ & $\begin{array}{r}56 \\
85 \\
125\end{array}$ & $\begin{array}{l}58 \\
22 \\
58\end{array}$ & $\begin{array}{r}148 \\
32 \\
159\end{array}$ \\
\hline$\%$ cultures positive & .. & 70 & 84 & $90 \cdot 6$ \\
\hline
\end{tabular}

In order to avoid the uncertainties of clinical diagnosis, the sensitivity of culture methods is often compared by figures for positives on smears and culture as shown in Table III. The figures from King's paper are directly abstracted, but those from McLeod's have been calculated from Table II of his paper.

These percentages are not the true percentages of isolation because $(a)$ false positive smears are included, and (b) positive cases with otherwise completely negative findings are excluded.

A true percentage of isolation is obtained from Table II, which is as accurate an estimate as can be made of the clinical facts, and gives 307 positive cultures out of 352 untreated cases $-87 \cdot 2$ per cent. The results indicate that the method of transporting swabs, coupled with the improvements in the cultural methods, gives results at least as good as the Leeds results, obtained by plating in the clinic and transporting the cultures to the laboratory. They are better than those reported by King in the difficulties of a wartime military hospital. We believe they demonstrate the importance of accurate bacteriological control of media and conditions of incubation, but it must be remembered that figures from different laboratories are rarely strictly comparable.

\section{Clinical Notes}

The material for this investigation was derived from an unselected group of female patients attending the Maudlin Street, Southmead, and Special
Diagnostic Clinics, Bristol, and included patients reporting voluntarily, ascribed sources of, or subsequent contacts with, gonococcal infection, women subjected to routine tests in illegitimate pregnancy, pregnant women who had developed vaginal discharges, etc. In each case a definite pattern of investigation was followed. A history of the present complaint was taken, including details of self-treatment or other measures applied, dates of possible exposures to infection, health of spouse, consort(s), etc. During a careful local examination, special attention was paid to obtaining specimens for laboratory investigation (usually from the urethra and cervix uteri, less frequently from the Bartholinian gland ducts or the rectum) free from contamination with vulval or vaginal secretion. A minimum of three tests at intervals of from three to seven days was accepted as adequate to exclude infection in patients with a negative history and normal clinical findings, whose consorts when examined were found to be non-infective. According to the degree of suspicion of infection in the individual case, the period of observation was lengthened, in many cases up to three months, with twelve or more slide and culture examinations in this time, no treatment likely to render the gonococcus unidentifiable being adopted.

In the final assessment of those cases in which there appeared to be non-agreement between the clinical and laboratory findings, a considered opinion was reached after the weighing-up of all the relevant factors : amongst these, accurate information as to the condition of the sexual partner was regarded as of the utmost importance. From this retrospective survey has emerged the fact, supported by a number of instances, that there can exist an undoubted gonococcal infection, often with minimal clinical signs, in which the gonococcus is non-demonstrable on repeated examination, yet in which, on epidemiological grounds, the infection is almost certainly present.

Into this category of epidemiological infections falls one group of ten patients, the ascribed sources of multiple infections and a second group of four patients, not included in the series of tests under review, who, despite negative tests over a period varying from six weeks to three months, were subsequently shown to be infective. From the first group (which is included in Table II), with ultimate clinic diagnosis positive and smears negative or doubtful, a typical case may be quoted :

A woman aged 27, of undoubtedly promiscuous habits, was described during February-March 1945 as being the source of gonococcal infection in three seamen. Multiple exposures were admitted : she douched regularly with dettol, but denied taking any sulphonamides. On 
examination, the only abnormalities detected were a small erosion of the cervix and a heavy muco-pus apron extruding from its canal. Laboratory investigations were negative. During the period of tests, approximately three weeks, another infection was ascribed to this source. The exposure was admitted. Subsequent tests were again negative. After full discussion of the position, this patient agreed to undergo treatment, a penicillinsulphonamide sequence being adopted. Default occurred one month later, the intervening tests being negative.

In September 1945 two further gonococcal infections were attributed to this patient. She was examined, again with " negative" results ; she asked for treatment but defaulted in a few weeks.

This patient apparently remained non-infective until March-April 1946, when she was stated to be the source of five infections, two of which were seen in this clinic. Her tests for gonorrhœa at another clinic were then stated to be positive.

In the second group one case may be quoted as illustrative :

A man aged 40, married, contracted gonorrhœa from an extra-marital exposure. The incubation period was eight days, and the wife was exposed on the sixth day, that is, two days before the onset of the discharge. The husband was treated with penicillin and passed a surveillance period of six months uneventfully. The wife, aged 28 , was under observation for three months, during which period she showed no clinical signs of infection, and the laboratory tests were consistently negative. She was believed to have escaped infection and was discharged.

Regular coitus with a condom was begun, without permission, about the fourth month after the husband's first attendance, neither spouse developing any symptoms. One month after final clearance was given, unprotected intercourse was resumed. Ten days later the husband reported with a florid gonorrhœa. The wife was clinically and bacteriologically negative. Extra-marital re-exposure was strenuously denied by both partners.

In view of the possibility of asymptomatic infection in the wife, treatment of both was advised and was carried out, the subsequent history to date indicating that both parties have remained " cured" non-infective.

In the first group of cases, douching, or selfmedication with sub-curative doses of sulphonamides, may have resulted in failure to recognize the gonococcus, but this did not obtain in the second group, in which one is forced to a conclusion of infective asymptomatism.

It is felt that more complete correlation of epidemiological data would lead to the recognition of a much greater number of such similar cases. At the same time it must be accepted that the diagnosis of "epidemiological gonorrhœa" must not be lightly made.

The recognition of such cases must inevitably lead to a wider appreciation of the difficulties of laboratory confirmation of diagnosis and the necessity for further research into improvement of methods of recognition of the $N$. Gonorrheere.

\section{Gonococcal Complement-Fixation Test}

This test has been almost completely abandoned in this laboratory since 1945 , as very few diagnostic positive findings were being obtained at that date. This was in spite of the fact that considerable reliance had been placed on this test in Bristol before the war. McLeod comments on the reduction in the number of positives obtained in Leeds (see Table $\mathrm{X}$ of his paper). In 1937-44 there were 34 per cent. positive, in 1945-6 only 11 per cent. Price, in a recent communication (1949), contrasts the steady rise, with the number of weeks after exposure, until 100 per cent. positives were obtained at the fifth week in 1933, with the slower rise to only 50 per cent. positives after six weeks in 1946-8. He points out that one of two things may have happened : (1) the patients are not reacting now as they did in the presulphonamide era, or (2) the complement-fixation test is no longer as sensitive as it was.

In Bristol the percentage of positive tests in 1936 was 36 per cent., and in 1945 only 9 per cent. This is a very similar finding to that obtained in Leeds and London. It seems unlikely that three different antigens, prepared by different methods from local strains, should simultaneously decrease in sensitivity to a similar degree, and it thus seems likely that the results are due to diminished antibody formation caused by the more rapid cures resulting from sulphonamide and penicillin. An examination of the Bristol patients' records shows no alteration in the method of selection which could explain this change.

It seems reasonable to suppose that the maintenance of bactericidal concentrations of a drug in the blood would bring to an end the stimulation by fresh antigenic material of antibody formation. The rapid killing of the organism would make the infection equivalent to only "one dose of vaccine". Those cases which might fail to respond to penicillin would be just those in which the gonococcal antigens were shut off from the circulation and in which antibody formation would be expected to be deficient. Whether sulphonamides were likely to be as efficient in freeing the circulation of gonococcal antigen is more questionable, especially as some degree of sulphonamide resistance is more prone to develop, and as the concentrations capable of maintenance in the blood are bacteriostatic rather than bactericidal.

To compare the effect of sulphonamides, the percentage of positive gonococcal complement fixation tests was examined for the year 1940, before the introduction of penicillin. The percentage in 
Bristol was 32 per cent., a figure not significantly different from the 1936 value, before sulphonamides were used, but very different from the 9 per cent. obtained in 1945, when penicillin was in use.

It thus seems possible that the diminishing positive results of the gonococcal complement-fixation test are due to the lack of antibody formation when penicillin therapy is effectively used. When it is remembered that a positive result may be obtained in meningococcal infections (Cruickshank, 1941 ; Lewis, 1941), and also in N. catarrhalis infections (Price, 1933), it becomes highly probable that this test is no longer of practical value in diagnosis.

\section{Culture Media for the Routine Examination of the Gonococcus}

(a) Mixtures for Preserving Swabs

(1) Crystal-Violet/Blood.-The results described were obtained with a modification of Cox and McDermott's mixture described by Harber (1947). A stock mixture is prepared by adding $1 \mathrm{ml}$. of 1 per cent. crystal-violet aqueous solution to $150 \mathrm{ml}$. of glass distilled water, containing $15 \mathrm{mg}$. $p$-aminobenzoic acid previously autoclaved at $10 \mathrm{lb}$. pressure for 20 minutes. For use, equal parts of freshly defibrinated or citrated sterile rabbit blood are added to the stock mixture. About $1 \mathrm{ml}$. of the mixture is introduced into the bottom of each swab tube, which should be a narrow tube (less than $1 \mathrm{~cm}$. in diameter, see figure). The swabs, on wooden applicators, are pushed only into the upper part of the tube, or, if it is to be posted, are sent in a separate tube so that they are dry until the specimen is taken. They are then pushed down into the liquid for transport back to the laboratory. If the swab is not plated out on the day of collection it should be kept overnight in the ice chest to obtain the maximum survival of gonococci. Glassdistilled water and wooden applicators avoid metallic contamination, which rapidly destroys the gonococcus.

(2) Thallium Acetate/Blood.-The substitution of $1 / 5,000$ thallium acetate for $1 / 30,000$ crystal-violet in the

TABLE IV

\begin{tabular}{|c|c|c|c|}
\hline & Advantage & $\begin{array}{c}\text { No } \\
\text { advantage }\end{array}$ & Total \\
\hline $\begin{array}{l}\text { Thallium acetate } . . \\
\text { Crystal-violet } \quad .\end{array}$ & $\begin{array}{r}17 \\
6\end{array}$ & $\begin{array}{l}25 \\
36\end{array}$ & $\begin{array}{l}42 \\
42\end{array}$ \\
\hline \multirow[t]{2}{*}{ Total .. } & 23 & 61 & 84 \\
\hline & \multicolumn{3}{|l|}{$P=0.007$} \\
\hline $\begin{array}{l}\text { Thallium acetate }+ \text { crystal- } \\
\text { violet } 0 \\
\text { Crystal-violet alone } \quad . .\end{array}$ & $\begin{array}{l}7 \\
8\end{array}$ & $\begin{array}{l}39 \\
38\end{array}$ & $\begin{array}{l}46 \\
46\end{array}$ \\
\hline Total & 15 & 77 & 92 \\
\hline$\chi^{2}=0.08$ & $P=0.77$ & & \\
\hline
\end{tabular}

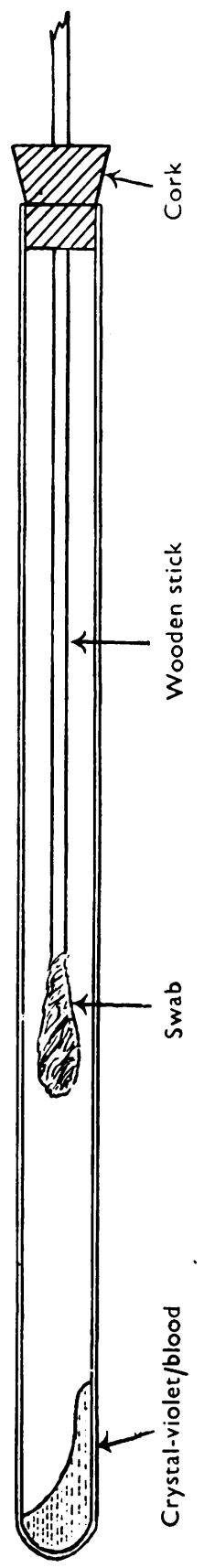

FIG.-Swab tube, actual size. 
above mixture was investigated by Cooper and Linton (1947) and shown to be an advantage in reducing more contaminant organisms and allowing more colonies of gonococcus to be identified. Since the publication of that paper a mixture of thallium acetate of $1 / 5,000$ and crystal-violet $1 / 30,000$ has also been tested in the blood and $p$-aminobenzoic acid.

It is seen from these comparisons (Table IV) that thallium acetate alone gave the best results, and the difference from crystal-violet is significant. Occasionally, however, crystal-violet or a mixture gives an advantage. Probably this is when a particular contaminant is present which thallium acetate fails to inhibit. The mixture is no better than crystal-violet alone though it may be that at these combined concentrations some inhibition of the gonococci may sometimes occur.

\section{(b) The Medium for Growing the Gonococcus}

Low temperature Meat Extract.-This type of extract is used by Anderson and others (1931) for diphtheria media and contains valuable nutrient qualities absent in the more heated media. The lean beef from which it is prepared should be freed as far as possible from gross fat, and should not be contaminated with the dye used to mark condemned meat. It should not have been frozen, and should be free from putrefactive changes. A quantity of $1,000 \mathrm{~g}$. is minced, mixed with $800 \mathrm{ml}$. of glass distilled water, extracted in a water bath at $50^{\circ} \mathrm{C}$. for one hour, filtered through cotton wool, and made up to $1,000 \mathrm{ml}$;; $20 \mathrm{~g}$. Proteose No. 3 peptone and $5.0 \mathrm{~g}$. sodium chloride are added, mixed well, and adjusted to $p \mathrm{H} 7.5$ (usually $42 \mathrm{ml}$. $\mathrm{NaOH}$ is required-but the quantity required should be estimated by titration of a convenient amount). This is replaced on the water bath at $50^{\circ} \mathrm{C}$. for a further 15 minutes, and is filtered through a Chardin filter paper (usually adequate for clarification), and then through a sterilized Chamberland type sterilizing filter. $80 \mathrm{ml}$. volumes are collected in sterile flasks of at least $150 \mathrm{ml}$. capacity and stored in the ice chest till required, but they must be used within one week as enzyme action may cause the accumulation of amino acids, which are toxic to the gonococcus. Digest broths or highly digested peptones are also unsuitable for this reason.

The peptone in this medium has been increased to 2 per cent. as against McLeod's original 1 per cent. This is held to be justified because, although peptone is toxic to the gonococcus if it is heated, the effect is neutralized by heated blood-and the amount of blood in the final medium has been doubled. Heating of the peptone has also been reduced to a minimum.

Agar Solution.-It is very important that the consistency of the medium for the growth of the gonococcus should be as soft as practicable. Modern agars are much more variable in setting strength than were pre-war supplies, and we have had continually to modify the previously recommended amount of agar to maintain this consistency. Some batches of agar are toxic for the gonococcus, but it has been shown that this toxicity is neutralized by the addition of starch (Gould and others, 1944). We added starch in a concentration one-tenth that of the agar used, to keep the ratio the same as in
Mueller's paper. $36-60 \mathrm{~g}$. Difco Bacto agar in $1,200 \mathrm{ml}$. glass distilled water, with $0 \cdot 3-0.5$ per cent. starch, was steamed till it dissolved. The $p \mathrm{H}$ was adjusted to 7.5 with $\mathrm{N} . \mathrm{NaOH}(7-12 \mathrm{ml}$.) and the mixture steamed for 20 minutes at $5 \mathrm{lb}$. pressure, filtered through muslin, and bottled in 100-ml. quantities in bottles able to take $300 \mathrm{ml}$. These were re-autoclaved for 20 minutes at 10-lb. pressure.

Blood.-Sterile rabbit blood was collected from the ear vein into flasks containing sterile 10 per cent. sodium citrate in distilled water; citrate solution/blood $=1 / 10$.

p-Aminobenzoic Acid.-0.25 par cent. in distilled water was autaclaved for 20 minutes at $10 \mathrm{lb}$.

Complete Medium.-Non-nutrient agar (prepared as above) was melted and cooled to $70^{\circ} \mathrm{C} .80 \mathrm{ml}$. unheated candle-filtered broth, $40 \mathrm{ml}$. sterile rabbit blood, and $4 \mathrm{ml}$. $p$-aminobenzoic acid solution were added. These were mixed well and placed in a water bath at $75^{\circ} \mathrm{C}$. for 10 or 15 minutes, and shaken at intervals until the medium became a chocolate colour. The medium was poured into plates to a depth of $5 \mathrm{~mm}$. and stored in the ice chest.

Cultivation.-Plates are warmed to $37^{\circ}$ C. before inoculation, but are not opened to dry except where condensation water is excessive in quantity. The swab from the blood mixture is inoculated on to the plate, heavily over half, and spread with the loop over the rest. The culture is placed in a glass jar covered with a vaselined plate, and a lighted candle is put inside before sealing. We have found this method adequate and more convenient than the 8 per cent. $\mathrm{CO}_{2} /$ air from cylinders previously used, and it has the advantage of producing water of condensation on the inside of the vessel. Care should be taken not to overheat cultures by candle before it is extinguished-not too large a jar should be used. Incubation is at $36^{\circ} \mathrm{C} . \pm 1^{\circ} \mathrm{C}$.

Examination.-Plates are examined after forty-eight hours, all apparently negative plates being treated with $1 / 2$ per cent. tetra-methyl $p$-phenylene diamine solution to ensure that no oxidase-positive colony is missed. Oxidase-positive colonies are examined by Gram stain and sub-cultured, and Gram-negative diplococci are tested for their sugar fermentations in blood broth medium (Harber, 1947).

\section{Conclusions}

1. The value of smears for the diagnosis of gonorrhœa in the female is limited ; 16 per cent. of cases are missed and false positives are given in an equal percentage of negative patients.

2. If the criteria are made more strict so that false positives are largely avoided, less than half the female cases yield positive smears.

3. Properly controlled culture methods detect more true positives than smears. They eliminate false positives, and give no doubtful results.

4. Adequate methods of preserving swabs overnight exist. Isolation of gonococci from 87 per cent. 
of female cases was obtained by crystal-violet/blood mixtures for preservation and improved heated blood media for culture. The details of the methods used are important and are described.

5. Thallium acetate/blood mixtures give even better results.

6. The antibody production of patients treated with penicillin has become so much less than it was in the years before its introduction that the usefulness of the gonococcal complement-fixation test has largely disappeared. The percentage of positive results from routine sera submitted to the laboratory has fallen from over 30 per cent. before penicillin to under 9 per cent. since its introduction.

We wish to record our thanks to Mr. Harber for the careful preparation of media, which contributes so greatly to success in the isolation of gonococci, to $\mathrm{Mr}$. Guise for his care of the gonococcal cultures, and to Mr. Nicholls for his care in controlling the technique of the gonococcal complement-fixation tests over a period of many years.

\section{REFERENCES}

Anderson, J. S., Happold, F. C., McLeod, J. W., and Thomson, J. G. (1931). J. Path. Bact., 34, 667.

Cooper, K. E., and Linton, A. H. (1947). Month. Bull. Min. of Hlth. and Publ. Hlth. Lab. Service, 6, 204.

Cruickshank, R. (1941). J. Path. Bact., 52, 142.

Eldering, G., and Palser, E. (1946). Amer. J. Publ. Hlth., 36, 1022.

Gould, R. G., Kane, L. W., and Mueller, J. H. (1944). J. Bact., 47, 287.

Harber, G. D. (1947). Brit. Inst. Med. Lab. Tech., 13, 53.

King, A. J., and Gallagher, E. (1946). Lancet, 1, 916.

Lewis, F. J. W. (1941). Paper read at Pathological Society (July, 1941, in Bristol). Unpublished.

M.R.C. Special Report Series (1923). Report No. 19 : "The Laboratory Diagnosis of Gonococcal Infections." London.

McLeod, J. W., Coates, J. C., Happold, F. C., Priestley, D. P., and Wheatley, B. (1934). J. Path. Bact., 39, 221. (1947). British Journal of Venereal Diseases, 23, 53.

Price, I. N. O. (1933). " Complement Deviation Test for Gonorrhœa." London C.C.

-(1949). British Journal of Venereal Diseases, 25, 67.

Stuart, R. D. (1946). Glasgow med. J., n.s., 27, 131. 